\title{
ORIGINAL ARTICLE \\ An investigation of seasonal variation in leisure-time physical activity in persons with spinal cord injury
}

\author{
M-J Perrier ${ }^{1}$, AE Latimer-Cheung ${ }^{1}$, KAM Ginis ${ }^{2}$ and the SHAPE-SCI Research Team
}

Study design: Secondary cross-sectional analyses of a cohort.

Objectives: To examine seasonal variation in total moderate-to-vigorous leisure-time physical activity (MV-LTPA), exercise and sport participation in a cohort of individuals with spinal cord injury (SCI).

Setting: Community (Ontario, Canada).

Methods: Participants with SCI $(n=695)$ completed telephone interviews regarding their involvement in MV-LTPA along with social cognitive predictors of MV-LTPA. Logistic regression was used to predict the impact of season on participation in MV-LTPA, exercise and sport. Hierarchical linear regression was used to examine seasonal variation in min per day of MV-LTPA in the active sub-cohort ( $n=342$ ) with a specific focus on exercise (for example, wheeling), and sport (for example, sledge hockey).

Results: Logistic regressions revealed that season did not predict whether participants engaged in MV-LTPA, exercise or sport. Linear regressions revealed that individuals in the active sub-cohort who completed the questionnaire during the winter reported engaging in less MV-LTPA than those who were interviewed in summer $\left(\beta_{\text {summer }}=0.14, P<0.05\right)$. This pattern was observed for exercise $\left(\beta_{\text {summer }}=0.16, P<0.05 ; R^{2}\right.$ change $\left.=0.018\right)$ but not for sport $\left(\beta_{\text {summer }}=0.076, P=0.68 ; R^{2}\right.$ change $\left.=0.014\right)$.

Conclusion: Individuals with SCI report less exercise and total LTPA accrued during the winter months; sport was found to be an exception to this case.

Spinal Cord (2012) 50, 507-511; doi:10.1038/sc.2012.11; published online 6 March 2012

Keywords: spinal cord injury; season; leisure-time physical activity; exercise after injury; sport participation

\section{INTRODUCTION}

A substantial body of evidence supports the relationship between moderate-to-vigorous leisure-time physical activity (MV-LTPA); the physical activities that individuals engage in during their spare time, such as going to the gym or playing a sport, ${ }^{1}$ and decreased morbidity and mortality among individuals with spinal cord injury (SCI), ${ }^{2,3}$ Indeed, MV-LTPA offers many physical benefits for individuals with SCI such as increased muscular strength and decreased muscular atrophy ${ }^{3}$ along with an increased sense of well-being and happiness, and reduced pain. ${ }^{3,4}$

Despite these benefits of MV-LTPA, a growing body of evidence suggests that many individuals with SCI are sedentary; approximately $50 \%$ participate in no LTPA whatsoever. ${ }^{5}$ This low participation rate is often attributed to many factors such as poor weather, lack of motivation, time and access to facilities for activity. ${ }^{6}$ Although people with SCI frequently cite weather as a physical activity barrier, ${ }^{7}$ there is no research, to our knowledge, that has specifically addressed and quantified the influence of weather as a barrier to MV-LTPA access for this population. Understanding the impact of weather on MV-LTPA participation among people with SCI will enable practitioners to better focus interventions to increase MV-LTPA during the times of the year that individuals struggle to be active. This topic is of particular interest given that a season-LTPA relationship has been demonstrated in the general population. ${ }^{8}$

A systematic review of the evidence supports the notion that total energy expenditure decreases in the winter months for the general population in climates with distinct seasonal weather patterns. This decrease was attributed to shorter days and adverse weather conditions. ${ }^{8}$ Weather had a significant effect on moderate intensity physical activity, accounting for as much as $42 \%$ of the variance in LTPA behaviour. ${ }^{8}$ Part of this decrease in physical activity during winter was due to changes in the amount people walked, the most common form of physical activity in the general population. ${ }^{9,10}$ This decrease was especially apparent during periods of continuous versus sporadic bouts of adverse weather. ${ }^{8}$

The purpose of this study was to examine if an association between season and LTPA also is present in the SCI population. Researchers have noted that among people with SCI patterns of LTPA participation are highly variable. ${ }^{11}$ Although several factors have been suggested to influence these patterns (for example, pain, weather), few have been examined empirically. Weather is a particularly relevant factor to consider given that adverse weather, such as snow and ice, may present substantial physical barriers to participation in both exercise, in terms of wheeling outdoors for exercise, as well as for sport participation, in terms of getting to and from facilities. Accordingly, the study was carried out in Ontario, Canada where there is a large difference in weather across seasons particularly between summer and winter making this province an ideal geographical area from which to draw participants for this study. Indeed, research by McColl et al. ${ }^{12}$ suggests that weather restricts mobility for Canadians with SCI more than American and British comparison groups, presumably because of greater seasonal variability in Canadian weather. We hypothesized that, similar to the general population, MV-LTPA would vary across season for individuals with SCI. We predicted that during the cold

${ }^{1}$ School of Kinesiology and Health Studies, Queen's University, Kingston, Ontario, Canada and 2Department of Kinesiology, McMaster University, Hamilton, Ontario, Canada Correspondence: M-J Perrier, School of Kinesiology and Health Studies, Queen's University, 28 Division Street, Room 402A, Kingston, Ontario, Canada K7L 3N6. E-mail: marie-josee.perrier@queensu.ca

Received 17 July 2011; revised 20 January 2012; accepted 26 January 2012; published online 6 March 2012 
winter months, rates of inactivity would be higher. Furthermore, for those individuals who do at least some MV-LTPA, min per day of MVLTPA would be lower in the winter, compared with during the relatively warmer spring, summer and fall seasons. Our rationale for this hypothesis was that in most regions of Ontario, the sidewalks and streets are often snowy and icy during the winter months, which may provide a physical barrier for wheeling and other outdoor activities; the physical barrier that season presents is an important aspect to note given that wheeling is one of the primary sources of LTPA among persons with SCI. ${ }^{13}$ During the spring and fall months, there may be less snow and fewer cold days, presenting less of a barrier to MV-LTPA. Therefore, MV-LTPA may be higher during these months than during winter.

We also were interested in whether season was related equally to sport and exercise participation. This analysis was based on the notion that (a) sport organizations often provide opportunities to participate in both summer and winter sports; (b) the competitive season for sport, such as rugby, often spans across more than one season and (c) sport practices and games are more often scheduled than exercise. Thus, sport participation may be less affected by seasonal variation than exercise participation. We expected to see more variations across season for individuals involved in exercise (for example, wheeling, lifting weights) in comparison with individuals involved in sports such as wheelchair basketball and rugby. We tested these hypotheses using a cross-sectional model to examine if season is related to the amount of physical activity individuals accrue.

\section{METHODS}

This study was a sub-analysis of the Study of Health and Activity in People with SCI (SHAPE-SCI). The full methodology and participant inclusion criteria for
SHAPE-SCI and its measures are reported elsewhere. ${ }^{14}$ As a summary of the methods, a large cohort of community-dwelling individuals with chronic SCI was recruited to participate in three telephone interviews with a trained interviewer over the course of 18 months. Data reported in this study were from the baseline telephone interviews that took place between January 2006 and June 2007.

\section{Participants}

Participants $(n=695)$ were recruited from four rehabilitation centres across Ontario for the SHAPE-SCI. ${ }^{14}$ Participants were recruited from a database of patients who had given consent to be contacted for research purposes as well as through notices in SCI-specific publications and newspaper advertisements. Eligible participants were Ontarians with a traumatic SCI that required assistance with mobility outside of the home. All participants were required to speak English, be 18 years of age or older and be $>12$ months post-injury. The research ethics boards at each participating site approved the study. Participants' demographic and injury characteristics are summarized in Table 1.

\section{Measures}

A number of demographic and injury characteristics were measured including age, sex, years post-injury, pre-injury LTPA, injury severity and mode of mobility. Age was reported in years and verified by checking the calculated age from the birth date. Sex was dummy coded using 0 and 1 , where 0 represented male and 1 represented female. Years post-injury was calculated in years by calculating the time between the injury date and the first data collection interview. Pre-injury LTPA was measured by asking the number of days per week individuals were active in moderate-to-heavy intensity activity for at least $30 \mathrm{~min}$ before injury. Injury severity was defined by the International SCI Core Data Set definitions such that injury severity was coded as a composite of injury level and completeness as indicated by the ASIA rankings. ${ }^{15}$ As a result, individuals were classified into one of the four following groups: (1) C1 to C4, ASIA grade A to C; (2) C5 to C8, ASIA grade A to C; (3) T1 to S5, ASIA grade A to C; and (4) ASIA grade D. Mode of mobility was classified

Table 1 Demographic and injury characteristics of participants in any LTPA

\begin{tabular}{|c|c|c|c|c|}
\hline \multirow[t]{2}{*}{ Variable } & \multicolumn{4}{|c|}{$\angle T P A$} \\
\hline & $\begin{array}{l}\text { Entire cohort } \\
\qquad(\mathrm{n}=695)\end{array}$ & $\begin{array}{c}\text { Any LTPA } \\
(\mathrm{n}=342) M(\text { s.d. }) ; \mathrm{n}(\%)\end{array}$ & $\begin{array}{c}\text { Exercise } \\
(\mathrm{n}=301) M(\text { s.d. }) ; \mathrm{n}(\%)\end{array}$ & $\begin{array}{c}\text { Sport } \\
(\mathrm{n}=152) M(\text { s.d.); } \mathrm{n}(\%)\end{array}$ \\
\hline Age (years) & $47.1(13.5)$ & $46.2(14.2)$ & $47.0(14.9)$ & $43.4(12.5)$ \\
\hline Years since injury (years) & $15.3(11.1)$ & $13.2(10.1)$ & $12.5(10.1)$ & $14.5(9.8)$ \\
\hline Men & $531(76.4 \%)$ & $265(77.5 \%)$ & $301(75 \%)$ & $152(80 \%)$ \\
\hline \multicolumn{5}{|l|}{ Mobility (CPA classifications) } \\
\hline Manual chair & $389(56 \%)$ & $202(59.1 \%)$ & $156(51.8 \%)$ & $120(78.9 \%)$ \\
\hline Power chair & $221(31.8 \%)$ & $90(26.3 \%)$ & $97(32.2 \%)$ & $21(13.8 \%)$ \\
\hline Walker, braces, cane, crutches & $85(12.2 \%)$ & $50(14.6 \%)$ & $48(15.9 \%)$ & $11(7.2 \%)$ \\
\hline \multicolumn{5}{|l|}{ Injury severity } \\
\hline C1-C4; ASIA A, B, or C & $75(10.8 \%)$ & $30(8.8 \%)$ & $28(9.3 \%)$ & $8(5.3 \%)$ \\
\hline C5-C8; ASIA A, B, or C & $184(26.5 \%)$ & $86(25.1 \%)$ & $74(24.6 \%)$ & $38(25.3 \%)$ \\
\hline T1-S5; ASIA A, B or C & 255 (36.7\%) & $126(36.8 \%)$ & $105(34.9 \%)$ & $68(45.3 \%)$ \\
\hline ASIA D & $172(24.7 \%)$ & $97(28.4 \%)$ & $91(30.2 \%)$ & $36(24.0 \%)$ \\
\hline Moderate/heavy intensity LTPA (min per day) & $18.6(33.9)$ & $28.0(34.0)$ & $22.7(28.1)$ & $46.5(46.6)$ \\
\hline \multicolumn{5}{|l|}{ Season of interview } \\
\hline Spring & $188(27.1 \%)$ & $88(25.7 \%)$ & $81(26.9 \%)$ & $41(27.0 \%)$ \\
\hline Summer & $201(29.0 \%)$ & $107(31.3 \%)$ & $91(30.2 \%)$ & $47(30.9 \%)$ \\
\hline Fall & 135 (19.5\%) & $66(19.3 \%)$ & $53(17.6 \%)$ & $33(21.7 \%)$ \\
\hline Winter & $170(24.5 \%)$ & $81(23.7 \%)$ & $76(25.2 \%)$ & 31 (20.4\%) \\
\hline
\end{tabular}

Abbreviations: CPA, Canadian Paraplegic Association; LTPA, leisure-time physical activity. Some participants declined to provide certain information. Hence, $n<342$ for some variables. Table adapted from Martin Ginis et al. $.5,13$ 
according to the categories provided by the Canadian Paraplegic Association where 1 represented a manual chair user, 2 represented a power chair user and 3 represented a gait aid user. ${ }^{16}$

Season was determined by the date of the data collection interview. Interviews that took place between 22 March and 20 June were coded as spring, between 21 June and 20 September were coded as summer, between 21 September and 20 December were coded as fall, and those between 21 December and 31 March were coded as winter.

The Physical Activity Recall Assessment for People with SCI (PARA-SCI), an SCI-specific LTPA measure, was used to measure the amount of MV-LTPA an individual engaged in over the previous 3 days. ${ }^{17}$ Individuals were mailed or emailed a chart that defined four SCI specific, physical activity intensities: nothing at all was defined as no physical effort; mild intensity activity was described as activities that require very light effort; moderate intensity activity was described as those that feel like some physical effort; and heavy intensity activity was described as any activity that required maximal physical effort. All daily physical activities were recalled and classified according to intensities for the 3 days before the interview. In this analysis, only minutes of MV-LTPA were used and classified into sport or exercise. Minutes of moderate and heavy intensity sport (including all reported sport activities such as sledge hockey, wheelchair basketball), exercise (including all reported exercise activities such as wheeling, resistance training) and total MV-LTPA (including all reported sport and exercise activities) were calculated as a daily averages. Participation status in each activity was determined by dichotomizing the sport, exercise, and total MV-LTPA variables $(0=$ inactive; $1=$ active). For each variable, participants who reported $0 \mathrm{~min}$ of activity were considered inactive and those reporting $>0 \mathrm{~min}$ were coded as active. This measure has demonstrated criterion and convergent validity as well as test-retest reliability. The PARA-SCI has also been validated for telephone use. The total number of minutes of physical activity has been found to have a high correlation with physical activity measured by indirect calorimetry, an objective measure of physical activity. ${ }^{11,17}$

\section{Data analysis}

To examine whether season was related to rates of inactivity, we conducted three logistic regressions predicting participation status in MV-LTPA, exercise, and sport. A logistic regression was conducted as a first step, given that the MVLTPA data were highly skewed (that is, 50\% reported no MV-LTPA) and could be best conceptualized as being comprised of two sub-cohorts-active and inactive individuals. Next, we conducted three hierarchical linear regressions predicting min per day of participation in MV-LTPA, sport and exercise for the cohort of individuals who were classified as 'active' (that is, $>0 \mathrm{~min}$ per day of MV-LTPA). Only the active cohort was used in these analyses, given the large number of zeros that would dilute the effect of season on MV-LTPA within those who are active. For each model, age, sex, injury status, years post-injury and mode of mobility were included as covariates in the first step because they predict MV-LTPA participation and differed significantly between seasonal groups. ${ }^{6,18,19}$ Season was entered in the second step. In this analysis, season was contrast coded with winter as the referent category. All analyses were completed in PASW Statistics v.18 (SPSS Inc., Chicago, IL, USA).

\section{RESULTS}

The majority of the sample was male (76.5\%) and had an SCI for an average of 13 years (Table 1). The majority were also manual wheelchair users $(59.1 \%)$ and had an ASIA classification higher than D $(71.6 \%)$. On average, the total amount of time spent in moderate-toheavy intensity LTPA per day was $28.0 \mathrm{~min}$ (s.d.=34.0); $22.7 \mathrm{~min}$ (s.d.=28.1) were spent in exercise and $46.5($ s.d.=46.6) were spent in sport (Figure 1). Detailed information about the duration and types of activities is available elsewhere. ${ }^{20}$

\section{Impact of season on any MV-LTPA participation}

Season did not predict whether participants engaged in MV-LTPA (odds ratio $(\mathrm{OR})_{\text {spring }}=1.00,95 \%$ confidence interval $(\mathrm{CI})=0.64-1.56$; $\mathrm{OR}_{\text {summer }}=1.43,95 \% \mathrm{CI}=0.93-2.20 ; \quad \mathrm{OR}_{\mathrm{fall}}=1.17,95 \% \mathrm{CI}=0.72-$ 1.89). Similarly, season did not predict participation in sport or exercise. The only variable that predicted exercise participation was years post-injury. Participants injured more recently were more likely to participate in any exercise $(\mathrm{OR}=0.96 ; 95 \% \mathrm{CI}=0.95-0.98)$. Age was the only variable to predict sport participation. Participants who were younger $\left(\mathrm{OR}_{\mathrm{age}}=0.96 ; 95 \% \mathrm{CI}=0.91-0.98\right)$ were more likely to be active at any sport (Table 2). Thus, there are important demographic differences between those who are active and those who are not.

\section{Impact season on duration of MV-LTPA}

The participants who reported any MV-LTPA comprised the 'active sub-cohort'. Among active participants, those whose MV-LTPA data were collected during the summer reported an estimated extra $7 \mathrm{~min}$ per day of MV-LTPA than those who provided MV-LTPA data in winter $\left(\beta_{\text {summer }}=0.14, P=0.01 ; R^{2}\right.$ change $\left.=0.012\right)$; although the standardized $\beta$ indicated a relatively small effect. Participants who reported on their MV-LTPA in spring and fall did not report more MV-LTPA than those who provided LTPA data in winter ( $\beta_{\text {spring }}=0.047, P=0.97 ; \beta_{\text {fall }}=0.047, P=0.44$ ). Sex and age were significant correlates of MV-LTPA; injury severity and mode of mobility approached significance. Participants who were female and older reported significantly less min per day of MV-LTPA than those who were male and younger (Table 2).

When MV-LTPA was separated into sport and exercise activities, differences in the predictive value of season were found. In the exercise model, the only significant predictor of moderate-to-heavy intensity exercise was season. Individuals who were interviewed during the summer reported more minutes of exercise than those who were interviewed in the winter $\left(\beta_{\text {summer }}=0.16, P=0.006 ; R^{2}\right.$ change $\left.=0.018\right)$; although the effect was small. ${ }^{21}$ Contrary to the models for exercise and total MV-LTPA, there was no difference in the minutes spent in sport for those interviewed in summer compared with those interviewed in winter $\left(\beta_{\text {summer }}=0.076, P=0.68 ; R^{2}\right.$ change $\left.=0.014\right)$. The only covariates that remained significant in the model for sport were age and injury status. Participants who were older and had higher injuries reported less minutes in sport than those who were younger and had lower injuries.

\section{DISCUSSION}

Season has a more complex relationship with MV-LTPA for people with SCI than originally anticipated. Our results showed that season does not distinguish between participants who do, versus do not,

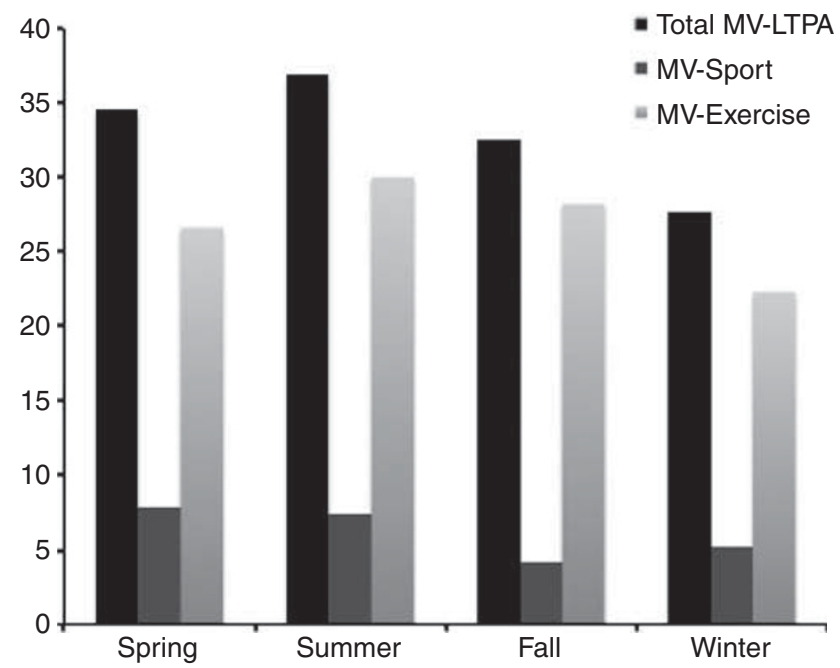

Figure 1 Minutes per day of LTPA reported by season. 
Table 2 Linear regression results for three LTPA models

\begin{tabular}{|c|c|c|c|c|c|c|}
\hline \multirow[t]{2}{*}{ Variable } & \multicolumn{3}{|c|}{ Full sample } & \multicolumn{3}{|c|}{ Active cohort } \\
\hline & LTPA OR (CI) & Sport OR (Cl) & Exercise $O R(\mathrm{Cl})$ & $\angle T P A \beta$ & Sport $\beta$ & Exercise $\beta$ \\
\hline Age & $1.00(0.99-1.01)$ & $0.95(0.91-0.98)$ & $1.00(0.99-1.02)$ & $-0.12 *$ & $-0.22 *$ & -0.053 \\
\hline $\operatorname{Sex}^{\mathrm{a}}$ & $1.29(0.88-1.87)$ & $1.45(0.60-3.51)$ & $1.26(0.86-1.84)$ & $0.11^{*}$ & $0.14^{+}$ & 0.095 \\
\hline Years post injury & $0.96(0.94-0.98)$ & $0.98(0.94-1.03)$ & $0.96(0.95-0.98)$ & -0.028 & -0.054 & -0.016 \\
\hline \multicolumn{7}{|l|}{ Injury status ${ }^{b}$} \\
\hline C1-C4; ASIA A-C & $0.94(0.48-1.85)$ & $0.51(0.054-4.76)$ & $0.99(0.50-1.97)$ & -0.056 & $-0.16^{+}$ & 0.007 \\
\hline C5-C7; ASIA A-C & $1.01(0.61-1.68)$ & $0.86(0.33-2.28)$ & $1.06(0.63-1.76)$ & -0.013 & $-0.25^{*}$ & 0.11 \\
\hline T1-S5; ASIA A-C & $0.93(0.58-1.50)$ & $0.56(0.23-1.37)$ & $1.04(0.64-1.68)$ & $-0.13^{+}$ & $-0.26^{*}$ & -0.042 \\
\hline ASIA D & Ref & Ref & Ref & Ref & Ref & Ref \\
\hline \multicolumn{7}{|l|}{ Season $^{\mathrm{c}}$} \\
\hline Spring & $1.00(0.64-1.56)$ & $0.75(0.029-1.98)$ & $1.10(0.70-1.73)$ & 0.047 & -0.059 & 0.039 \\
\hline Summer & $1.43(0.93-2.20)$ & $1.23(0.49-3.13)$ & $1.44(0.93-2.23)$ & $0.14^{*}$ & 0.076 & $0.16^{*}$ \\
\hline Fall & $1.17(0.72-1.89)$ & $1.04(0.36-3.05)$ & $1.25(0.77-2.03)$ & 0.047 & -0.029 & 0.054 \\
\hline Winter & Ref & Ref & Ref & Ref & Ref & Ref \\
\hline \multicolumn{7}{|l|}{ Mode of mobility ${ }^{d}$} \\
\hline Manual chair & $1.29(0.70-2.37)$ & $2.18(0.63-7.51)$ & $1.21(0.65-2.23)$ & $0.18^{+}$ & 0.22 & 0.063 \\
\hline Power chair & $0.74(0.39-1.42)$ & $0.096(0.09-1.02)$ & $0.79(0.42-1.52)$ & -0.022 & 0.056 & -0.15 \\
\hline Walker, cane or braces & Ref & Ref & Ref & Ref & Ref & Ref \\
\hline Overall model significance & - & - & - & $F(9,576)=4.47 *$ & $F(11,140)=1.86^{*}$ & $F(11,285)=2.11$ * \\
\hline Step $1 R^{2}$ (change in $R^{2}$ ) & 0.069 & 0.19 & 0.056 & $0.073(0.012)$ & $0.11(0.014)$ & $0.057(0.018)$ \\
\hline
\end{tabular}

Abbreviations: $\mathrm{Cl}$, confidence interval; LTPA, leisure-time physical activity; OR, odds ratio.

aReferent category: male.

bReferent category: ASIA D, all levels.

CReferent category: winter.

dReferent category: walker, cane or braces

$* P<0.05,+P<0.10$.

LTPA was measured in average min per day.

engage in MV-LTPA, sport or exercise. However, season is related to the amount of daily MV-LTPA that active participants report, particularly when exercise activities are taken into consideration. With respect to participation in MV-LTPA, there may be greater barriers other than season, such as program cost and availability, physical symptoms such as low energy and pain and lack of information about physical activity. ${ }^{3}$ As our results would suggest, once individuals overcome barriers to any activity, season has a role in how much MV-LTPA is then reported such that in months were weather is poor and unpredictable, the amount of MV-LTPA accumulated is more variable.

Accordingly, the level of MV-LTPA in the active sub-cohort reported significantly between summer and winter. As previous research suggests, individuals in the general population are less active during the winter than summer as adverse weather and temperature form barriers to exercise; this is a pattern noted in our cohort as well. ${ }^{8}$ As previously mentioned, previous research suggests that it is continuous poor weather that decreases MV-LTPA; ${ }^{8}$ therefore, it is possible that the sporadic precipitation and milder temperatures in fall and spring do not influence MV-LTPA among people with SCI in the same way that winter does. Indeed research from McColl et al. ${ }^{12}$ also have suggested weather as a factor restricting mobility among Canadians with SCI. Van Staveren et al. ${ }^{22}$ found an estimated $17 \mathrm{~min}$ in LTPA difference between summer and winter; in our cohort, there was an approximate 7-min difference. The smaller difference likely is the result of a lower level of overall MV-LTPA in the SCI population compared with the general population..$^{5}$ Although smaller than in the general population, the difference observed in our cohort of indivi- duals with SCI is notable. Physical activity guidelines for the SCI population are lower than in the general population ( 40 min per week versus 150 min per week). ${ }^{23}$ A 7 -min decrease in activity is equivalent to almost $20 \%$ of the recommended amount of physical activity.

Interestingly, weather was related to participation in exercise activities such as outdoor wheeling. Understanding the influence of season on MV-LTPA activities such as exercise allows us to understand when to use resources to promote activities in this population. For example, knowing that individuals are less likely to exercise during the winter months allows health promoters to apply proportionally more resources such as increasing the amount of transportation to fitness facilities during winter and promotional materials. This type of temporal approach may help individuals with SCI accrue more minutes of activity year round.

An interesting finding is the robustness of sport against the influence of season such that there were no significant differences between min per day spent in sport across seasons. Part of this result may be explained by the fact that many adapted sports, such as wheelchair basketball and rugby, can be played indoors and thus are not directly influenced by adverse weather to the same extent as unstructured activities such as play or wheeling around the block; many sport practices require the same time commitment, which may help explain the lack of significant differences between seasons. Selfregulatory skills and social support have demonstrated a positive influence on physical activity participation; ${ }^{24}$ these are both inherent characteristics of sport. Indeed, adapted sport organizations often offer both summer and winter sport opportunities for people with SCI. For example, team sports involve others and have games and 
practices already planned, taking some of the burden of scheduling MV-LTPA off of the individual. Furthermore in comparison with exercise, in the general population sport is often motivated by enjoyment and is done for the task itself, indicating a level of intrinsic motivation rather than extrinsic motivation; this means that those who participate in sport would be more likely to do so in the face of barriers, such as weather. ${ }^{25}$ Therefore, it may be possible that our participants who were involved in sport were highly motivated and found ways to get past the barriers of weather to make it to practice whereas individuals who exercised were less motivated to persist in the face of seasonal barriers. Future research questions examining the characteristics of sport and testing whether a sport intervention is effective at maintaining MV-LTPA participation in the same individual across seasons is warranted.

\section{Limitations}

A limitation of this study is the use of season as an indicator of weather characteristics. Given the size of the cohort and the broad geographical area in which participants lived, it was not possible to use the specific temperature and precipitation data for each participant's locale. However, it is possible that the influence of weather and precipitation is more pronounced than we have estimated in this study by having the calendar determine seasons; indeed this may explain the relatively small effect between season and MV-LTPA. A second limitation is the use of self-reported MV-LTPA data, and in particular one that used 3 days as an indicator of daily MV-LTPA; as a result of the 3-day recall format some participants may not have had the opportunity to report usual physical activity that occurred outside of the specific recall days (for example, regular weekend curling matches). Finally, given the cross-sectional analysis, it is difficult to make any within person remarks concerning the relationship between season and MV-LTPA over time. Further research examining the influence of season-specific factors such as temperature and precipitation is warranted.

\section{CONCLUSION}

As with the general population, individuals with SCI are less likely to report engaging in MV-LTPA during the winter months as they are during the summer months. Indeed, season has a small association with min per day of MV-LTPA; however, of interest, individuals involved in sport reported more min per day of activity across all seasons. Therefore, the promotion of sports may be a viable strategy for increasing and maintaining year-round MV-LTPA in the SCI population, particularly through encouraging involvement in both winter and summer sports. Given the seasonal fluctuation in exercise behaviours, such as outdoor wheeling, a proportionally higher effort should be spent to ensure individuals are able to overcome weather barriers and maintain activity year round.

\section{DATA ARCHIVING}

There were no data to deposit.

\section{CONFLICT OF INTEREST}

The authors declare no conflict of interest.

\section{ACKNOWLEDGEMENTS}

The research project was supported by an Operating Grant from the Canadian Institutes of Health Research (CIHR; Grant no. MOP 57778). Preparation of the paper was supported by a Mentor-Trainee Award from the Ontario
Neurotrauma Foundation (KAMG and AELC), a New Investigator Award (KAMG), a Canada Research Chair (CIHR) award (AELC) and a Social Sciences and Humanities Research Council Doctoral Fellowship (MJP).

1 Bouchard C, Shepard RJ. Physical activity, fitness, and health: the model and key concepts. In: Bouchard C, Shepard RJ, Stephens T (eds). Physical Activity, Fitness, and Health: International Proceedings and Consensus Statement. Human Kinetics: Champaign, 1994 pp 77-88.

2 Hicks AL, Martin KA, Latimer AE, Craven C, Bugaresti J, McCartney M. Long-term exercise training in persons with spinal cord injury: effects on strength, arm ergometry performance and psychological well-being. Spinal Cord 2003; 41: 34-43.

3 Wolfe DL, Martin Ginis KA, Latimer AE, Foulon BL, Eng JJ, Hicks AL et al. Physical Activity and SCI. In: Eng JJ, Teasell RW, Miller WC, Wolfe DL, Townson AF, Hsieh JTC, Connolly SJ, Mehta S, Sakakibara BM (ed). Spinal Cord Injury Rehabilitation Evidence. Version 3.0. 2010.

4 Martin Ginis KA, Jetha A, Mack DE, Hetz S. Physical activity and subjective well-being among people with spinal cord injury: a meta-analysis. Spinal Cord 2010; 48: 65-72.

5 Martin Ginis KA, Latimer AE, Arbour-Nicitopoulos KP, Buchholz AC, Bray SR, Craven $\mathrm{BC}$ et al. Leisure time physical activity in a population-based sample of people with spinal cord injury part I: demographic and injury-related correlates. Arch Phys Med Rehab 2010; 91: 722-728.

6 Tasiemski T, Bergstrom E, Savic G, Gardner BP. Sports, recreation and employment following spinal cord injury - a pilot study. Spinal Cord 2000; 38: 184.

7 Martin KA, Latimer AE, Hanely H, Francoeur C, Watson KN. Sustaining exercise motivation and participation among people with spinal cord injury: lessons learned from a 9-month intervention. Palaestra 2000; 38: 38-40.

8 Tucker P, Gilliland J. The effect of season and weather on physical activity: a systematic review. Public Health 2007; 121: 909-922.

9 Dannenberg AL, Keller JB, Wilson PWF, Castelli WP. Leisure time physical activity in the Framingham offspring study. Am J Epidemiol 1989; 129: 76-88.

10 Yusuf HR, Croft JB, Giles WH, Anda RF, Casper ML, Caspersen CJ et al. Leisure-time physical activity among older adults. Arch Intern Med 2010; 156: 1321-1326.

11 Latimer AE, Martin Ginis KA, Craven BC, Hicks AL. The physical activity recall assessment for people with spinal cord injury: validity. Med Sci Sports Exercise 2006; 38: 208-216.

12 McColl MA, Charlifue S, Glass C, Savic G, Meehan M. International differences in ageing and spinal cord injury. Spinal Cord 2002; 40: 128-136.

13 Martin Ginis KA, Arbour-Nicitopoulos KP, Latimer AE, Buchholz AC, Bray SR, Craven $\mathrm{BC}$ et al. Leisure time physical activity in a population-based sample of people with spinal cord injury part II: activity types, intensities, and durations. Arch Phys Med Rehab 2010; 91: 729-733.

14 Martin Ginis KA, Latimer AE, Buchholz AC, Bray SR, Craven BC, Hayes KC et al. Establishing evidence-based physical activity guidelines: methods for the Study of Health and Activity in People with Spinal Cord Injury (SHAPE SCI). Spinal Cord 2008; 46: 216-221.

15 DeVivo M, Biering-Sorenson F, Charlifue S, Noonan V, Post M, Stripling T et al. International spinal cord injury data set core data set. Spinal Cord 2006; 44: 540.

16 Canadian Paraplegic Association. The Workforce Participation Survey of Canadians with Spinal Cord Injury. Canadian Paraplegic Association: Ottawa, 2000.

17 Martin Ginis KA, Latimer AE, Hicks AL, Craven BC. Development and preliminary evaluation of an activity measure for people with spinal cord injury. Med Sci Sports Exercise 2005; 37: 1099-1111.

18 Wu SK, Williams T. Factors influencing sport participation among athletes with spinal cord injury. Med Sci Sports Exercise 2001; 33: 177-182.

19 Foreman PE, Cull J, Kirkby RJ. Sports participation in individuals with spinal cord injury: demographic and psychological correlates. Int J Rehab Res 1997; 20: 159-168.

20 Martin Ginis KA, Arbour-Nicitopoulos KP, Latimer AE, Buchholz AC, Bray SR, Craven $\mathrm{BC}$ et al. Leisure time physical activity in a population-based sample of people with spinal cord injury part II: activity types, intensities, and durations. Arch Phys Med Rehabil 2010; 91: 729-733.

21 Hedges LV, Olkin I. Statistical Methods for Meta-Analysis. Academic Press: New York, 1985.

22 Van Staveren WA, Deurenberg P, Burema J, DeGroot LC, Jautvast JG. Seasonal variation in food intake, pattern of physical activity and change in body weight in a group of young adult Dutch women consuming self-selected diets. Int J Obesity 1986; 10: $133-145$.

23 Martin Ginis KA, Hicks AL, Latimer AE, Warburton DE, Bourne C, Ditor S et al. Development of evidence-informed physical activity guidelines for people with spinal cord injury. Spinal Cord 2011; 49: 1088-1096.

24 Rhodes RE, Pfaeffli L. Mediators of physical activity behaviour change among adult non-clinical populations: a review update. Int J Behav Nutr Phy Activity 2010; 7: 37

25 Frederick CM, Ryan RM. Differences in motivation for sport and exercise and their relations with participation and mental health. J Sport Behav 1993; 16: 124. 